\section{OP0032 MALIGNANCIES AND SERIOUS INFECTIONS IN RANDOMISED CONTROLLED TRIALS OF JANUS KINASE INHIBITORS IN PATIENTS WITH RHEUMATOID ARTHRITIS: A SYSTEMATIC REVIEW AND META- ANALYSIS}

M.A. Lopez-Olivo ${ }^{1}$, J.H. Tayar ${ }^{1}$, N.V. Zamora ${ }^{2}$, G. Pratt ${ }^{3}$, M.E. Suarez-Almazor ${ }^{1}$. ${ }^{1}$ General Internal Medicine, The University of Texas, MD Anderson Cancer Center, Houston, USA; ${ }^{2}$ Rheumatology Section, Instituto de Rehabilitación Psicofísica, Buenos Aires, Argentina; ${ }^{3}$ Research Medical Library, The University of Texas, MD Anderson Cancer Center, Houston, USA

Background: Two JAK inhibitors are currently approved by different agencies worldwide for their use in patients with rheumatoid arthritis. The safety profile of these agents has been of interest since the approval of the first JAK inhibitor, particularly the risk of developing malignancies or serious infections.

Objectives: We conducted a systematic review and meta-analysis of phase 2 and phase 3 trials to evaluate these two outcomes in patients receiving JAK inhibitors for rheumatoid arthritis.

Methods: We performed a search in 5 electronic databases and also searched clinicaltrials.gov, Food and Drug Administration, and European Medicines Agency. In addition, the bibliography list of included studies was also screened to search for further citations not retrieved from other sources. We included controlled trials evaluating the efficacy of a JAK inhibitor (i.e., tofacitinib baricitinib, filgonitinib, peficinitinib, ABT-494, or decenotinib). Two reviewers independently screened studies, evaluated their risk of bias, and extracted data. Primary outcome data included number and type of malignancies and infections and time point of occurrence when available. The reported publications was considered the primary source of data for all trials. Serious infections were defined as those meeting the criteria for a serious adverse events such as a fatal, life threatening, or leading to hospitalisation.

Results: Thirty-one trials were analysed, reporting data on 13945 patients. Follow-up of the included trials ranged between 4 and 52 weeks with a median of 24 weeks. The risk of attrition bias was judged low for most studies. The reported rates of malignancies and serious infections across studies ranged from $0 \%$ and $0.7 \%$ to $2.0 \%$, and $5.4 \%$, respectively. Most commonly reported malignancies were lung cancer, melanoma, nonmelanoma skin cancer, basal cell and squamous cell carcinoma. Patients receiving the combination of JAK inhibitor plus methotrexate or JAK inhibitor monotherapy had higher rates of malignancies, compared with methotrexate between 12 and 24 weeks before the rescue treatment was implemented, but the difference did not reach statistical significance (odds ratio $(\mathrm{OR}) 2.48,95 \%$ confidence interval $(\mathrm{Cl}) 0.76$ to 8.11 and $1.39,95 \% \mathrm{Cl}$ : 0.21 to 9.11 , respectively). Regarding serious infections, the JAK inhibitor groups had similar rates to those observed in the control groups (OR $0.90,95 \% \mathrm{Cl}: 0.38$ to $0.92,95 \% \mathrm{Cl}: 0.35$ to 2.43 , respectively). However, there was a dose-response effect with higher rates of serious infections observed in those patients receiving higher doses of JAK inhibitors.

Conclusions: Although not reaching statistical significance, in the currently available RCTs, the rates of malignancy were higher in the JAK inhibitors groups compared to their controls. The rates of serious infections were similar between JAK inhibitor groups and their controls, but were dose-dependent. Future studies should aim to indirectly compare each JAK inhibitor to evaluate if these safety signals are also drug dependent and to assess risk per type of malignancy or infection.

Disclosure of Interest: M. Lopez-Olivo: None declared, J. Tayar: None declared, N. Zamora: None declared, G. Pratt: None declared, M. Suarez-Almazor Consultant for: Pfizer, Endo Pharmaceuticals, and Bristol-Myers Squibb DOI: 10.1136/annrheumdis-2018-eular.7079

\section{OP0033 EFFECT OF A STEP-UP OR STEP-DOWN IN TOFACITINIB DOSE ON EFFICACY AND SAFETY IN PATIENTS WITH RHEUMATOID ARTHRITIS IN LONG- TERM EXTENSION STUDIES}

R.B. Mueller ${ }^{1}$, H. Schulze-Koops ${ }^{2}$, D.E. Furst ${ }^{3}$, S. Cohen ${ }^{4}, K^{\prime}$ Kwok ${ }^{5}$, A. Maniccia ${ }^{5}$, L. Wang ${ }^{6}$, E. Akylbekova ${ }^{7}$, G. Ackermann ${ }^{8}$, J. von Kempis ${ }^{1} .{ }^{1}{ }^{K}$ Kantonsspital St. Gallen, St. Gallen, Switzerland; ${ }^{2}$ Klinikum der Universität München, Munich, Germany; ${ }^{3}$ UCLA, Los Angeles, CA; ${ }^{4}$ Metroplex Clinical Research Center and University of Texas Southwestern Medical Center, Dallas, TX; ${ }^{5}$ Pfizer Inc, New York, NY; ${ }^{6}$ Pfizer Inc, Groton, CT; ${ }^{7} I Q V I A$, Durham, NC, USA; ${ }^{8}$ Pfizer AG, Zurich, Switzerland

Background: Tofacitinib is an oral Janus kinase inhibitor for the treatment of rheumatoid arthritis (RA). Efficacy and safety of tofacitinib 5 and $10 \mathrm{mg}$ BID have been shown in long-term extension (LTE) studies up to 114 months.

Objectives: To assess the impact of tofacitinib dose changes on efficacy and safety in patients (pts) who increased (step-up) or who decreased (step-down) dose, vs pts who remained on the same dose when entering LTE studies.
Methods: In this exploratory, post hoc analysis, data were pooled from 2 openlabel LTE studies (NCT00413699 [ongoing; database not locked at ${ }^{\text {Jan }} 2016$ datacut]; NCT00661661) of pts with RA who had participated in Phase (P) 1/2/3 tofacitinib index studies and had $>81$ days of tofacitinib exposure (to allow $>2$ assessments) in each period (P1/2/3 index and LTE). Dose changes from index study dose were mandated by protocol (at LTE entry) or at the investigator's discretion (during LTE). This analysis only included pts who remained on their initial/ changed dose in the LTE. Pts were analysed in 4 groups: $5 \mathrm{mg} \mathrm{BID} \mathrm{[index] \rightarrow -}$ $10 \mathrm{mg}$ BID [LTE] (Step-up; $\mathrm{n}=833$ ); $5 \mathrm{mg}$ BID [index] $\rightarrow 5 \mathrm{mg}$ BID [LTE] (Remain $5 ; n=248) ; 10 \mathrm{mg}$ BID [index] $\rightarrow 10 \mathrm{mg}$ BID [LTE] (Remain 10; $n=951$ ); $10 \mathrm{mg}$ BID [index] $\rightarrow 5 \mathrm{mg} \mathrm{BID} \mathrm{[LTE]} \mathrm{(Step-down;} n=234$ ). To determine if initial efficacy (last index study assessment) affects response following dose change on LTE entry, sub-groups for the Step-up and Remain 5 groups were defined based on initial ACR20 response, and sub-groups for the Step-down and Remain 10 groups were defined based on initial ACR50 response. Efficacy was assessed up to Month 12 in the LTE based on $\triangle \mathrm{DAS} 28-4(\mathrm{ESR})$. Exposure-adjusted event rates (pts with events/100 pt-yrs) are presented for the most common adverse events (AEs) for the entire LTE study exposure.

Results: No statistically significant differences in $\triangle \mathrm{DAS} 28-4(\mathrm{ESR})$ were observed between the Step-up and Remain 5 groups (figure 1A), whether or not they had an initial ACR20 response (data not shown). In general, no significant differences in $\triangle \mathrm{DAS} 28$-4(ESR) were observed between the Step-down and Remain 10 groups (figure 1B), whether or not they had an initial ACR50 response (data not shown). The rates and types of AEs were similar across all groups (table 1).

Abstract OP0033 - Table 1. Summary of AEs in the LTE study

\begin{tabular}{|c|c|c|c|c|}
\hline & $\begin{array}{c}\text { Step-up: } \\
5 \text { to } \begin{array}{c}10 \mathrm{mg} \\
\mathrm{N}=833\end{array}\end{array}$ & $\begin{array}{c}\text { Remain on } \\
5 \mathrm{mg} B 10 \\
\mathrm{~N}=248\end{array}$ & 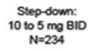 & 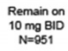 \\
\hline Total years of exposure & 2720 & 007 & 822 & 3030 \\
\hline Discontinued due to AEs, n & 207 & 53 & 48 & 221 \\
\hline \multicolumn{5}{|c|}{ Most common AE system organ dasses, n (EAER): EAER >10.00 in any group } \\
\hline Intections and infestatoons & $578(21.18)$ & $171(18.85)$ & $141(17.16)$ & $\cos (21.88)$ \\
\hline Gastrointestinal disorders & $257(2.41)$ & $03(10.25)$ & $83(10.10)$ & $200(8.77)$ \\
\hline Musaloskeletetal and connective Essuve disorders & $323(11.83)$ & $78(2.50)$ & $58(8.81)$ & $308(12.08)$ \\
\hline \multicolumn{5}{|c|}{ Most common AE preteresed terms, n (EAER). EAER $>3.00$ in any group } \\
\hline Nasopharnoits & $101(3.70)$ & $70(7.71)$ & $03(7.68)$ & $148(4.81)$ \\
\hline Upper respiratory tract intection & $130(5.00)$ & $37(4.07)$ & $33(4.01)$ & $170(5.90)$ \\
\hline Bronchitis & $\infty 2(3.02)$ & $41(4.51)$ & $20(243)$ & $137(4.52)$ \\
\hline Urinary tract intection & $121(4.43)$ & $12(1.32)$ & $18(210)$ & $115(3.70)$ \\
\hline Herpes zoster & $94(3.44)$ & $34(3.74)$ & $18(219)$ & $85(3.13)$ \\
\hline
\end{tabular}

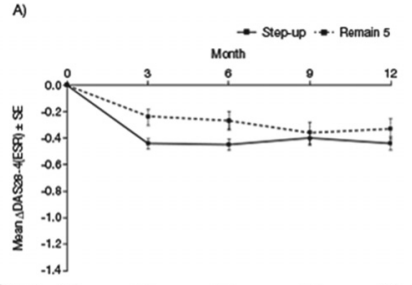

B)

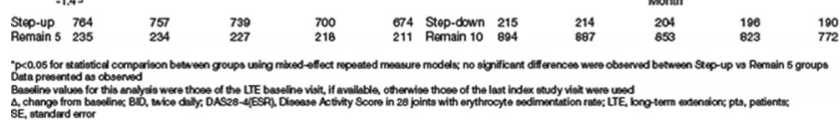

Abstract OP0033 - Figure 1. Mean $\triangle \mathrm{DAS28}-4(\mathrm{ESR})$ over time for A) Step-up pts and those who remained on tofacitinib $5 \mathrm{mg}$ BID and B) Step-down pts and those who remained on tofacitinib $10 \mathrm{mg} \mathrm{BID}$

Conclusions: In pts with RA, the safety profile was similar regardless of dose change. Step-up from tofacitinib 5 to $10 \mathrm{mg} \mathrm{BID}$, or step-down from 10 to $5 \mathrm{mg}$ BID, did not affect efficacy over 12 months vs remaining on the same dose, and was not influenced by initial response. Conclusions were limited by small pt numbers in some groups, the open-label design and inclusion of pts in the LTE who showed tolerability for tofacitinib and drug retention.

\section{REFERENCE:}

[1] Wollenhaupt J, et al. Arthritis Rheumatol 2017;69(suppl 10):Abstract 522

Acknowledgements: Study sponsored by Pfizer Inc. Medical writing support was provided by A MacLachlan of CMC and funded by Pfizer Inc.

Disclosure of Interest: R. Mueller: None declared, H. Schulze-Koops: None declared, D. Furst Consultant for: Pfizer Inc, S. Cohen Grant/research support from: AbbVie, Amgen, Astellas, Bristol-Myers Squibb, Eli Lilly, Genentech, Gilead, Janssen, Novartis, Pfizer Inc, Roche, Sandoz, Consultant for: AbbVie, Amgen, Astellas, Bristol-Myers Squibb, Eli Lilly, Genentech, Gilead, Janssen, Novartis, Pfizer Inc, Roche, Sandoz, K. Kwok Shareholder of: Pfizer Inc, Employee of: 
Pfizer Inc, A. Maniccia Shareholder of: Pfizer Inc, Employee of: Pfizer Inc, L. Wang Shareholder of: Pfizer Inc, Employee of: Pfizer Inc, E. Akylbekova Consultant for: Pfizer Inc, Employee of: IQVIA, G. Ackermann Employee of: Pfizer AG, J. von Kempis: None declared

DOI: 10.1136/annrheumdis-2018-eular.3110

\section{OP0034 LONG-TERM EFFECTIVENESS OF THE COBRA SLIM REMISSION INDUCTION AND TREAT TO TARGET STRATEGY IN PATIENTS WITH EARLY RHEUMATOID ARTHRITIS LACKING CLASSICAL MARKERS OF POOR PROGNOSIS: 2 YEAR RESULTS OF THE CARERA TRIAL}

V. Stouten ${ }^{1}$, J. Joly ${ }^{2}$, S. Pazmino ${ }^{1}$, K. Van der Elst ${ }^{1,2}$, D. De Cock ${ }^{1}$, R. Westhovens ${ }^{1,2}, P$. Verschueren ${ }^{1,2}$, on behalf of the CareRA study group. ${ }^{1}$ Skeletal Biology and Engineering Research Centre, KU Leuven; ${ }^{2}$ Rheumatology, University Hospitals Leuven, Belgium

Background: EULAR guidelines recommend to treat all patients with early Rheumatoid Arthritis (eRA) with a combination of methotrexate (MTX) and a short-term course of Glucocorticoids (GC). The COBRA Slim strategy with MTX and a moderately dosed tapering down scheme of GC was effective, also in patients without classical markers of poor prognosis during the first year.

Objectives: To compare the outcomes of MTX with or without initial step-down GC in Low-Risk patients during the second year of the CareRA trial, in terms of disease control, safety and DMARD use.

Methods: CareRA is a two-year prospective investigator-initiated pragmatic multicentre RCT. DMARD naïve eRA patients were stratified into a High- or Low-Risk group based on classical prognostic markers (presence of erosions, RF, anti-CCP and DAS28-CRP). Low-Risk patients $(n=90)$ were randomised to either TightStep Up (TSU) with MTX $15 \mathrm{mg}$ weekly without GC or to COBRA Slim, a combination of MTX $15 \mathrm{mg}$ weekly and prednisone tapering down scheme starting at $30 \mathrm{mg}$, tapered to $5 \mathrm{mg}$ daily from w6 and stopped at w34. A treat-to-target approach was applied until year 1 and afterwards treatment was at the discretion of the rheumatologist. Proportions of DAS28-CRP remission at year 2 was a coprimary CareRA endpoint. Secondary outcomes were efficacy according to other remission criteria, EULAR/ACR response rates and functionality measured by HAQ (ITT analysis, last observation carried forward). Adverse events (AEs) and concomitant medication were registered.

Results: At year 2, $67.4 \%$ of Slim and $70.2 \%$ of TSU patients were in remission according to DAS28CRP ( $p=0.777$ ). Out of patients in DAS28CRP remission at year $1,80.0 \%(24 / 30)$ in the Slim group, versus $69.0 \%(20 / 29)$ in the TSU group remained in remission at every three-monthly evaluation until year 2 . Remission rates defined by Boolean criteria were higher in patients of the Slim (39.5\%) versus TSU group (19.1\%) ( $\mathrm{p}=0.033)$. Functionality measured by mean area under the HAQ curve over 2 years was better in Slim patients (38.3 \pm 47.2$)$ than in TSU patients $(56.4 \pm 48.7)(p=0.025)$. Other secondary efficacy outcomes did not differ

Abstract OP0034 - Table 1 Clinical outcomes during the second year per treatment arm

\begin{tabular}{|l|c|c|c|}
\cline { 2 - 4 } \multicolumn{1}{c|}{} & $\begin{array}{c}\text { COBRA slim } \\
(\mathbf{n}=\mathbf{4 3})\end{array}$ & $\begin{array}{c}\text { TSU } \\
(\mathbf{n}=\mathbf{4 7})\end{array}$ & p-value \\
\hline Remission DAS28-CRP year 2 & $29(67.4 \%)$ & $33(70.2 \%)$ & 0.777 \\
\hline DAS28-CRP change BL-year 2 & $2.2 \pm 1.8$ & $2.2 \pm 2.0$ & 0.929 \\
\hline DAS28-CRP change year 1-year 2 & $0.1 \pm 0.8$ & $0.0 \pm 0.9$ & 0.486 \\
\hline Mean AUC of DAS28CRP & $248.9 \pm 110.8$ & $266.1 \pm 82.3$ & 0.119 \\
\hline Good EULAR response at year 2 & $55.8 \%$ & $61.7 \%$ & 0.571 \\
\hline ACR50 improvement at year 2 & $25(58.1 \%)$ & $23(48.9 \%)$ & 0.382 \\
\hline ACR70 improvement at year 2 & $19(44.2 \%)$ & $15(31.9 \%)$ & 0.230 \\
\hline Remission CDAl year 2 & $20(46.5 \%)$ & $15(31.9 \%)$ & 0.156 \\
\hline Remission SDAI year 2 & $20(46.5 \%)$ & $15(31.9 \%)$ & 0.156 \\
\hline Remission Boolean year 2 & $\mathbf{1 7}(39.5 \%)$ & $\mathbf{9 ( 1 9 . 1 \% )}$ & $\mathbf{0 . 0 3 3}$ \\
\hline Mean AUC of HAQ & $\mathbf{3 8 . 3 \pm 4 7 . 2}$ & $\mathbf{5 6 . 4 \pm 4 8 . 7}$ & $\mathbf{0 . 0 2 5}$ \\
\hline Clinically meaningful HAQ change at year 2 & $53.5 \%$ & $59.6 \%$ & 0.561 \\
\hline HAQ = 0 at year 2 & $48.8 \%$ & $36.2 \%$ & 0.224 \\
\hline
\end{tabular}

DAS28-CRP $=28$ Joint disease activity score calculated with C-reactive protein; good EULAR response $=$ low disease activity with a DAS28-CRPchange $(B L-y e a r 2)>1.2 ; A U C=$ Area Under the Curve (BL-year 2); $\mathrm{HAQ}=$ health assessment questionnaire; clinically meaning ful $\mathrm{HAQ}$ change (BL-year 2$)=$ HAQ change $>0.22$. between the treatment arms. The total numbers of AEs reported as related to study therapy, were 69 in 34 TSU patients and 63 in 28 Slim patients. Biologicals were started in 14 Low-Risk patients (15.6\%), more specifically in 8 Slim and 6 TSU patients during the CareRA trial. At the year 2 visit $62.5 \%$ of Slim patients were on MTX monotherapy and $12.5 \%$ on a combination of csDMARDs. In the TSU group $58.5 \%$ was taking MTX as only DMARD, and $19.5 \%$ took a combination of csDMARDs. Out of all Low-Risk patients $11.0 \%$ (8/73) was taking oral GC at the year 2 visit, 5 patients in the TSU group and 3 patients in Slim group, all at a low dosages.

Conclusions: In eRA patients lacking classical markers of poor prognosis COBRA Slim showed persistently high remission rates and good disease control 2 years after initiating therapy in a treat to target setting. COBRA slim seems to be slightly more effective than TSU according to the year 2 Boolean remission criteria and the 2 year functionality AUC but the CareRA study was not powered for this analysis.

Disclosure of Interest: V. Stouten: None declared, J. Joly: None declared, S Pazmino: None declared, K. Van der Elst: None declared, D. De Cock: None declared, R. Westhovens: None declared, P. Verschueren Grant/research support from: unrestricted Pfizer chair for management of early RA DOI: 10.1136/annrheumdis-2018-eular.2535

\section{OP0035 UPADACITINIB AS MONOTHERAPY: A PHASE 3 RANDOMISED CONTROLLED DOUBLE-BLIND STUDY IN PATIENTS WITH ACTIVE RHEUMATOID ARTHRITIS AND INADEQUATE RESPONSE TO METHOTREXATE}

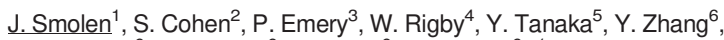

A. Friedman ${ }^{6}$, A. Othman ${ }^{6}$, H. Camp ${ }^{6}$, A. Pangan ${ }^{6} .{ }^{1}$ Med Univ of Vienna, Vienna,

Austria; ${ }^{2}$ Metroplex Clin Res Ctr, Dallas, USA; ${ }^{3}$ Leeds Inst of Rheum and

Musculoskeletal Med, Leeds NIHR BRC, UK, Leeds, UK; ${ }^{4}$ Dartmouth Coll,

Hanover, USA; ${ }^{5}$ Univ of Occ and Env Health, Kitakyushu, Japan; ${ }^{6}$ AbbVie, $N$

Chicago, USA

Background: Upadacitinib (UPA), an oral JAK inhibitor, showed efficacy in rheumatoid arthritis (RA) patients (pts) with an inadequate response to csDMARDs or bDMARDs on continuing stable csDMARD(s). ${ }^{12}$

Objectives: Safety and efficacy of switching to UPA $15 \mathrm{mg}$ or $30 \mathrm{mg}$ monotherapy vs continuing methotrexate (MTX) as a blinded study drug was evaluated in pts with inadequate response to MTX (MTX-IR).

Methods: Pts with active RA (TJC $\geq 6, \mathrm{SJC} \geq 6$, hsCRP $\geq 3 \mathrm{mg} / \mathrm{L}$ ) on stable MTX were enrolled and randomised 1:1:1 in a double-blind manner to once-daily (QD) UPA $15 \mathrm{mg}$ or $30 \mathrm{mg}$ monotherapy or to continue MTX (cMTX) at their prior stable dose. At BL, all pts discontinued prior MTX without washout and received PBO (for pts on UPA) or MTX at prior dose (cMTX) as blinded study drug. The primary endpoints at Week (Wk) 14 were the proportion of pts achieving ACR20, and the proportion achieving DAS28-CRP $\leq 3.2$ (NRI)

Results: 648 pts were randomised, all received study drug; 598 (92.3\%) completed 14 wks. BL demographics and disease characteristics were generally similar across arms. Both primary endpoints were met $(p<0.001)$; at Wk 14 , a significantly greater proportion of pts receiving UPA monotherapy (15 mg and $30 \mathrm{mg})$ vs cMTX achieved ACR20 (67.7\% and $71.2 \%$ vs $41.2 \%)$, and DAS28CRP $\leq 3.2$ (44.7\% and $53.0 \%$ vs $19.4 \%$ ) (table 1 ). All key secondary endpoints also showed UPA 15 and UPA 30 monotherapy to be superior to CMTX, including ACR50 (41.9\% and $52.1 \%$ vs $15.3 \%$ ), ACR70 (22.6\% and $33.0 \%$ vs $2.8 \%$ ) DAS28-CRP $<2.6$ (28.1\% and $40.5 \%$ vs $8.3 \%), \Delta \mathrm{HAQ}-\mathrm{DI}(-0.65$ and -0.73 vs -0.32). $\triangle$ SF-36 PCS and $\triangle$ Morning Stiffness data are also shown (table 1). The proportion of pts achieving CDAI $\leq 10$ was significantly greater with UPA 15 and 30 vs cMTX (34.6\% and $46.5 \%$ vs $24.5 \%$ ).

Adverse events (AEs) were reported at similar frequencies across arms; serious AEs were numerically higher in UPA 15 but similar between CMTX and UPA 30 (table 1). Numerically more infections were reported in CMTX and UPA 30 vs UPA 15. One serious infection each was reported in UPA 15 and CMTX, and none in UPA 30. Herpes zoster was more frequent in UPA 30 vs UPA 15 or cMTX. 3 malig nancies ( 1 in cMTX and 2 in UPA 15) and 3 adjudicated MACE (1 in UPA 15 and 2 in UPA 30 ) were reported. One adjudicated pulmonary embolism was reported (UPA 15) in a pt with known risk factors (BMI 36; on oestrogen therapy). One death (haemorrhagic stroke due to ruptured aneurysm) was reported in UPA 15. No TB, renal dysfunction or GI perforation was reported. Rates and types of laboratory abnormalities were consistent with prior UPA RA studies to date. 